\title{
Tax Risk Analysis of China's Enterprises in the Process of IPO Listing
}

\author{
Qiang'an Liu \\ Anhui University of Finance \& Economics
}

\begin{abstract}
Taxation has always been a major obstacle in the process of enterprise IPO. There are many tax-related problems in the process of IPO listing of small and medium-sized enterprises in China. In order to avoid the tax risk, we need to carry out various control and prevention in order to effectively deal with this obstacle.
\end{abstract}

Keywords: IPO listing; tax-related issues; tax control

DOI: $10.36012 /$ ems.v1i1.961

\section{A Tax Problem About China's Small and Medium-sized Enterprises in IPO which Left over from History}

$\mathrm{T}$ here are many sources of tax risk, one of which is the tax problem left over by history. When an enterprise owns the strength of equity financing through the capital market, it will find that it pays too much attention to economic interests and neglects the management of the enterprise. Taxation is the most prominent problem in these irregular management. In the first three years, enterprises should pay attention to tax issues, such as whether the tax categories, tax rates are legally compliant, and whether there are any tax violations.

First, the issue of tax reimbursement during the reporting period. There are many links in the process of IPO, including the declaration of financial statements. Because there may be errors before the original statements, tax reimbursement will occur if the adjustment of income and profit is involved in the process of correction. The nature and amount of relevant accounting errors determine the nature and amount of tax reimbursement. Different nature and amount may bring different results, and also determine whether it will audit successfully. On the nature of tax reimbursement. Accounting errors are composed of two parts, one is caused by errors, and the other is caused by fraud, which are obviously different in nature. If errors are caused by incorrect use of accounting methods or delays in processing accounting business during the missed confirmation period, they are caused by errors; if errors are caused by falsification of costs or income caused by revenue and profit reduction due to tax evasion in the past, they are fraudulent. About the amount of tax reimbursement. The nature of the two cases of tax reimbursement is determined, but the two cases are also very difficult to distinguish. If the amount of tax reimbursement exceeds half or more of the amount of tax payable in the relevant period, it is too large, and the tax reimbursement caused by errors usually does not cause such as this large amount of money, there 
will be very clear signs of fraud caused. Major tax reimbursement has violated the relevant provisions in essence, and it is undoubted that it has become a substantial obstacle. Audit risk of tax reimbursement. The delayed tax payment caused by the reimbursement will result in legally compulsory levy, not only that, but also negative impact on earnings per share and shareholders' earnings. The SFC now attaches great importance to the behavior of tax reimbursement. Generally, enterprises that have such behavior will delay at least one more full accounting year, which will miss the good time of listing. Enterprises will face great auditing risk if they pay taxes and fail to give reasonable explanation.

Secondly, tax evasion and tax evasion. Whether there are tax evasion and tax evasion in IPO declaration enterprises is also a key concern of the SFC.

In the process of auditing, the SFC will strictly check that there is no major violation of this kind of behavior. Legal factors, if they exist, will greatly affect the performance of enterprises, resulting in untrue performance. Phenomenon, then this link will obviously constitute a substantial obstacle to the listing of enterprises. Because many local governments are not rigorous in dealing with tax issues, the relevant provisions on tax revenue are also unclear.

Clearly, some enterprises will abuse public resources to impose improper taxes in the listed compa nies. Means of collection. In local governments, some tax evaders maliciously take advantage of loopholes in local tax regulations to steal. It is possible for taxpayers to order the tax authorities to identify their actions as non-material tax leakage through improper means. Acts, therefore, will not be severely punished. In view of these fraudulent tax evasion and tax evasion, the SFC has rectified the corresponding measures. The planned listed enterprises must attach great importance to them and strictly control them.

\section{Tax issues of enterprise change and reor- ganization about China's Small and Medi- um-sized Enterprises in IPO}

Firstly, the difference between tax revenue and accounting income caused by the change of accounting policy. In enterprises, tax revenue is mainly reflected in turnover tax and enterprise income tax. Before IPO, the accounting statements made by enterprises are mainly used to meet the tax demand. For the method of revenue recognition, enterprises usually make invoices, and in the process, they should always keep the declared tax revenue and report. The accounting income on the table is the same. Tax revenue has corresponding tax rules, and the recognition of income also has enterprise accounting standards as a reference, which must be strictly observed. Therefore, on the premise of not considering the taxable business of non-value-added tax, on the principle of confirmation, value-added Tax revenue and accounting income have different sources in essence, while corporate income tax revenue and accounting income are essentially identical. We should adhere to the principle of separating tax payment from accounting. Tax revenue should be treated according to tax rules and accounting standards. If there are income differences but still do not change the confirmation method, there will be persistent statement error correction, and there will naturally be significant persistent differences. In this way, it is likely to be hindered in the stage of IPO audit, which will bring trouble to the stage of listing.

Secondly, the tax issue of enterprise restructuring. Generally speaking, in order to pursue economies of scale, reduce their own operational risks and avoid the risk of mergers and acquisitions, enterprises will often further integrate and re-allocate resources before listing, that is, to restructure enterprises, so as to improve the efficiency of resource allocation. In the process of reorganization, enterprises will encounter many tax problems, such as whether the arrangement of resource integration and reallocation is more efficient in tax affairs, whether the reorganization will bring about larger tax costs, and how to calculate the receivables of the reorganization year if the reorganization in the middle of the year involves loss compensation and preferential inheritance. Income tax; whether the personal tax problem of enterprise managers and employees within the enterprise is handled properly, etc. If an enterprise can pay attention to the above problems at the first time, it will restructure its business and raise taxes. Planning effective links, so that not only can satisfy the business planning of enterprises, but also can play a role in reducing tax risk.

\section{Tax preference dependence about China's Small and Medium-sized Enterprises in IPO}

In practice, if the proportion of tax incentives accounted for more than $20 \%$ of the profits of each period, it 
would constitute a serious tax dependence, but also hinder the steady progress of the IPO process. In the first half of 2011, there were more than 20 SMEs and motherboard IPOs.

If not, more than $20 \%$ of enterprises have serious tax dependence. Local governments will always focus on protecting the listed companies, so it is easy to transfer their interests. Serious tax dependence will bring uncertain performance to enterprises, which makes it difficult for them to pass through the SFC. It becomes very difficult for them to succeed in listing.

\section{Measures for Enterprises to Avoid Tax-related Risks of IPO about China's Small and Medium-sized Enterprises}

First, clarify the tax strategy. In the restructuring of a group company, we should rationally structure the tax process of the subordinate company of the group, focusing on the following three points: firstly, to reduce tax risk, especially for those companies with upstream and downstream relationships within the group company, we should formulate reasonable internal transaction prices to prevent abnormal prices from being recognized as related transactions by the tax authorities; secondly, to reduce tax risk. In order to save taxes legally, it is particularly necessary to avoid duplicate payment of turnover tax when providing services or products within a group. Thirdly, to improve efficiency and avoid overly complex tax processes, which can easily lead to additional human costs and errors.

Secondly, design tax plan ahead of time. Practice has proved that tax planning in advance, in the process and afterwards should be ahead of time. First of all, we should consider the advance of tax planning in terms of time, and conduct preliminary investigation and scheme design as soon as possible. It is of great practical significance to actively design tax planning plan beforehand. It is suggested that enterprises should arrange the overall tax planning in advance, including the following specific points: Fiscal and taxation work is an important part of the development strategy of enterprise groups before the company goes public, so it faces a series of problems that need to be solved. After the implementation of the new Enterprise Income Tax Law and its implementing rules, it is necessary to pay close attention to and study the new tax policies matching it, and formulate corresponding countermeasures as soon as possible. At the time of policy adjust- ment, we need to carefully study the policy orientation embodied in the new tax law and adjust investment behavior in time. Make full use of favorable tax policies, especially preferential tax policies. If the tax incentives for investment are favorable, we should pay close attention to them. Tax planning is a basic right of taxpayers. The essence of tax planning is to lighten the burden of taxpayers. Taxpayers can reduce tax errors through tax planning, make full use of tax preferential policies, flexibly grasp and use tax policy differences, obtain the best and reasonable planning plan, and achieve considerable tax-saving benefits and legitimate income.

Preliminary preparations for tax-related activities are complex and substantial. Including collection of tax policies and regulations, formulation of plans, personnel composition, cooperation between the two sides, prior investigation and research, communication with tax authorities, etc.

Thirdly, pay attention to before listing tax issues. Capital market attaches great importance to the tax issues of enterprises, especially the three aspects of historical legacy, enterprise restructuring and transfer pricing. Before listing, enterprises should select senior financial and taxation intermediaries, conduct overall tax health checks on enterprises, and clean up the previous tax risks of enterprises. Design the optimal corporate structure, so that the tax burden of enterprises can be lowered to the minimum, and the operation effect can be the best. In addition, in order to avoid more supervision, some enterprises will choose to set up a cross-border company structure arrangement before listing overseas. These arrangements may face anti-tax avoidance adjustments because they involve the tax interests of cross-border countries or regions. Therefore, these enterprises should not only pay attention to their own tax laws, but also to international tax issues. Especially after the implementation of the new Enterprise Income Tax Law, the management of cross-border non-operating enterprises in China has become more and more stringent. The traditional method of building cross-border multi-layer structure to indirectly evade the income tax of the actual operating company has been strictly restricted in the new tax law. There have been quite a number of cases in recent one or two years. Enterprises should draw lessons from this and pay more attention to the relevant provisions on tax adjustment in the new enterprise income tax law. IV. 
Suggestions on the Development of Financial Management of Small and Medium-sized Enterprises in the Network Environment.

Finally, we should foresee the direction of fiscal policy and regulation adjustment as soon as possible. Successful planning needs to find planning space within the limits of existing laws and regulations. For example, in order to plan a year-end dividend distribution scheme for enterprises, we should use the concept of modern enterprise property rights system to determine the distribution relationship, and give due consideration to the labor dividend of employees, especially the income of human capital. If we are confined to the distribution concept of "who invests who benefits, no investment is not beneficial", which is stipulated in the current Company Law, and only consider the interests of shareholders, not human capital gains, such a distribution scheme is not optimal. Tax planning should foresee the direction of regulation adjustment as soon as possible. The fundamental reason lies in the contradiction between the activity, advance and legal stability and lag of the real economy. The advance of tax planning determines the high risk of tax planning. In practice, we must grasp the legitimacy of procedures and minimize operational risks.

\section{Reference}

[1] Qiang'an Liu. Introduces the centralized accounting model and its internal control method [J].Monthly Journal of Finance and Accounting, 2003 (08).
[2] Liu Hong. Talking about the cost and benefit of tax planning[J].Modernization of shopping malls,2007(09).

[3] Wu Yunfeng. Tax Risk Research in China [D].Jiangxi University of Finance and Economics, 2008.

[4] Luo Wen. Tax planning and analysis of small and medium-sized enterprises income tax [J].Entrepreneur World (Late issue),2011(04).

[5] Qiang'an Liu. Invisible Assets Measurement Based on Fair Value Domain Model [J].Financial Communication,2013 (10).

[6] Yu Xiangju. New requirements for enterprise financial management in the era of e-commerce [J].Times of Economy and Trade,2013(24).

[7] Tian Yixiu. Exploring the innovative thinking of the financial management mode of small and medium-sized enterprises under the network environment $[\mathrm{J}]$.Decision-making and information,2013(2).

[8] Qiang'an Liu, Tan Zhigang. Experiences and lessons from the real estate tax system and its relationship with local finance in the United States [J].Modernization of management,2013(08).

[9] Wang Xiaoyan, Zhao Zeyang. Talking about financial management and accounting innovation in the new economic era[J].China Business,2013(14).

[10] Feng Jianhua, Wang Wenqing. Handling and Case Analysis of Individual Income Tax in Equity Sale[J].Registered Tax Officer,2015(03)

[11] Qiang'an Liu. Discussion on Anti-money Laundering of Securities Companies Driven by Financial Science and Technology[J].Western Finance and Accounting, 2018(08).

[12] Qiang'an Liu. Research on the Construction of China's Multi-level Capital Market[J].Economist,2018(10). 